\title{
Status quo and development potential of full life cycle evaluation of construction waste
}

\author{
Jingming $\mathrm{Jia}^{1}$,Fumin Ren $^{1, *}$ and Jintong $\mathrm{Zhu}^{1}$ \\ ${ }^{1}$ School of Civil Engineering, Beijing Jiao Tong University, Beijing, China
}

\begin{abstract}
It is critically important to synthesize the life-cycle assessment (LCA) and construction waste content, especially in term in recycling of construction waste resources ${ }^{[1]}$ and optimizing critria in the lifecycle evaluation. That is, the development of construction waste resources is entitled to be boosted, as same as criteria and elements in periodic evaluation concentrating on the module of construction waste. This paper analyzes the disadvantages of construction waste and potential promotion in each stage, which is of great significance for improving the evaluation system and management of construction waste.
\end{abstract}

\section{Introduction}

The construction industry, as a pillar industry in China, has been in a state of rapid development. The problems exposed are: the exhaustion of building material resources and the surge of construction waste.According to relevant research, the production of construction waste in China accounts for $40 \%$ of the total urban waste, in comparison to the global construction industry accounts for $40 \%$ of the energy consumption, which has only generated $47 \%$ of the global waste. Moreover, there are many kinds of complex components, and the pollution degree caused by them is also different. All these mentioned factors have sharpened the conflicts between reusing and disposing of waste resources in Chinese construction industry.According to the Development Report on the Industrialization of Construction Waste Resources in China, from 2011 to 2019, the amount of construction waste generated by housing construction in China was as high as 977 to 2133 million tons, taking up about $30 \%$ to $40 \%$ of the total amount of municipal solid waste.However, the recycling rate of construction waste in China is still less than $5 \%{ }^{[2]}$ In the whole life cycle of buildings, waste of building materials and consumption of energy lead to serious environmental problems such as acidification, global warming, haze as well as ozone hole. In order to deter the environmental deterioration, it is estimated that, by $2030,65 \%$ of building materials in China and $75 \%$ of decoration waste are supposed to be recycled. Therefore, a full-developed evaluation covering the whole life cycle of construction waste is demanded to provide information support and approaching guidance for the sustainable development of construction waste.

The LCA of construction waste can summarize several kinds of factors that have a great impact on the environment from different urban cases, and at the same time, the hazard of construction waste can be quantitatively assessed according to the corresponding model. In addition, it can be used as one of the key evaluation standards of urban green construction.

\section{Full life cycle evaluation of construction waste}

\subsection{Definition of full life cycle evaluation of construction waste}

The whole life cycle impact assessment of construction waste is based on the life cycle assessment, which is an assessment method for the whole process of construction waste.The full life cycle impact assessment of construction waste can be regarded as the product of combining LCA with practical engineering and specialization in the field of construction waste. Life cycle assessment (LCA) is a globally recognized environmental load quantification standard ${ }^{[3]}$, which plays an important role in evaluating the environmental impact and resource consumption of product life cycle ${ }^{[4]}$. Foreign research on LCA has been half a century, mainly in the impact assessment of breakthroughs. Since 1990s, Life cycle assessment has become a research hotspot in domestic academic circles ${ }^{[5]}$. A large number of researchers have carried out a large number of studies in life cycle methodology research and specific materials and product applications. Yang Jianxin et al. established a method system to evaluate China's environmental impact and resource consumption, which provided a theoretical basis for domestic life cycle assessment research ${ }^{[6]}$.

So far, there have been several executions of whole life cycle impact assessment stagnated in some specific cases, for example. Therefore, Webber and his team, by using LCA evaluation model and practical application of the construction waste processing, after compareing direct landfill technology with the shenzhen city recycling

*Fuming Rem:fmren@bjtu.edu.cn 
program, figured out two approaches to evaluate the economic costs associated with the quantitative evaluation and environmental load.

With regard to some defects in the whole life impact assessment of construction waste, In order to improve the relevant knowledge system and enhance the reference value of its practical application, this paper analyzes the deficiency and potential developing direction of the full life cycle impact assessment of construction waste from two aspects $^{[7]}$.

\subsection{Indicators of full life cycle evaluation of construction waste}

According to the overall process of construction waste,the indexes of the impact assessment of the full life cycle of construction waste can be divided into the following parts:

\subsubsection{Evaluation on the source of construction waste}

The source of construction waste determines the outputing quantity of the entire building garbage and its initial impacts on the environment. The impact evaluation on the source includes the aseessments on the influences of building materials, soil quality in ocuupied constructing land, the overall regional planning, and the the surrounding water quality. In addition to assess the potential hazards of the materials used in buildings, the purpose of the evaluation stage is to find out the impacts of the buildings at the initial stage of construction on the surrounding environment.

\subsubsection{Transport process impact evaluation index}

According to relevant statistics, nearly $15 \%$ of the garbage in the source area is scattered on the way when it is transported to the disposal site or landfill site, which brings additional pollution burden to the nearby residents and the surrounding environment. Therefore, the reduction of garbage in the process of transportation has become an important index for the evaluation of the whole life cycle, which is mainly about the variation of garbage in the process of origin and disposal, the problem of too long transportation and the deterioration and oxidation of garbage.

\subsubsection{Impact evaluation index of disposal end}

Disposal sites and landfills have been the main "destination" of construction waste in the past two decades, and the final site's capacity, leaching toxicity, and disposal methods have become typical indicators of environmental impact. Excessive amount of one factor will harm the surrounding environment. For example, heavy metals in construction waste migrate to the deep soil, causing soil compaction and saline-alkali land production. Therefore, it is necessary to strictly control all elements at the disposal end.

\subsubsection{Impact evaluation index of remanufactured products}

Since the 13th Five-Year Plan, recycled products have been the main products of the national emphasis on the recycling of construction waste. Recycled products, such as recycled bricks and recycled concrete, have become the key evaluation indicators of recycled products in terms of their promotion scope and practical effect after application. Although it does not involve environmental pollution factors, it is of great significance to improve the recycling rate of construction waste, and it is necessary to become an evaluation project of the whole life cycle of construction waste ${ }^{[8]}$.

\section{Review of the full life cycle evaluation of construction waste}

\subsection{Source evaluation of construction waste}

At present, the sources of construction waste in China are widely distributed and the components are complex. According to the investigation of domestic demonstration cities, there are generally three classification methods: according to the source, according to the physical composition, and according to the reuse performance. Traditional construction waste will be divided into land excavation, the excavation of roads, the old building demolition, construction and building materials production and waste five categories, mainly by the sediment, crushed stone, waste mortar, brick and tile fragments, concrete, asphalt, plastic, scrap metal, waste wood and so on, but it is not clear for construction waste of scientific evaluation system. The lack of life cycle evaluation system leads to the lack of factual basis for the evaluation at the source of the life cycle of construction waste, which leads to the lack of accurate and scientific information in the whole evaluation system.

In order to improve this situation, typical evaluation

methods of construction waste from abroad can be used for reference, such as construction waste classification assessment, reuse product quality control and other technologies, to constantly improve China's construction waste classification system, and further promote the maturity of the evaluation system, the Fig. 1 shows the growing trend of standards related to construction waste. 


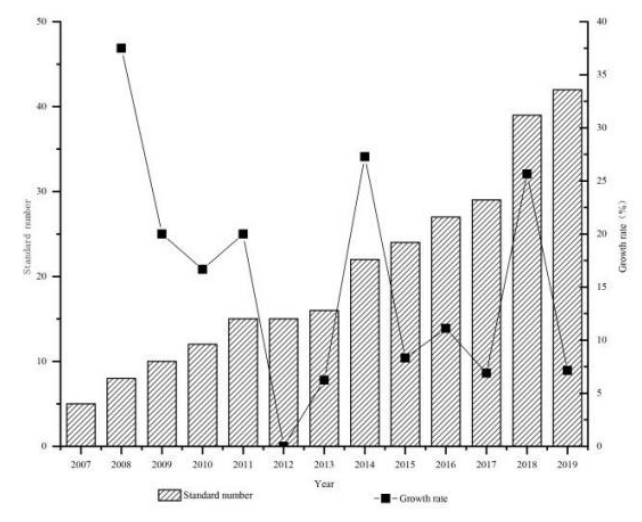

Fig1. The growing trend of standards related to construction waste

At the same timebased on the whole industry chain to carry out the evaluation of the life cycle of construction waste.

For different types of construction waste (take decoration waste as an example), different classification methods and information acquisition methods can be used. Through the analysis of decoration waste in Huzhou, Zhou Jijiao used the charging mechanism to obtain detailed information about the quantity and category of decoration waste on the one hand, and on the other hand, to promote the development of prefabricated building technology to achieve the reduction of decoration waste. Through the analysis of concrete examples to constantly improve the evaluation system of garbage, and finally build a construction waste in China in accordance with the actual life cycle evaluation system.

\subsection{Construction waste transport evaluation}

The construction waste transport process is in the position of connecting the past and connecting the future in the whole life cycle evaluation system. Safe and complete transport is the important premise to guarantee the origin of garbage and disposal site garbage, whose properties are unified. At the same time, it is also one of the important means to avoid the environmental pollution around the transportation. Therefore, the dynamic characteristics of construction waste in the transportation process should be included in the whole evaluation system.

After practical investigation, it is found that in most cities, transportation units control the disposal direction of construction waste, especially playing an important role in the optimization and allocation of construction waste in the aspect of "redundancy balance" resource recovery.For example, in the comprehensive utilization of earthworks, excavation is carried out in the early stage of A project, and the transport party is entrusted to carry out external transportation. The transport party will allocate some earthworks for backfilling in the later stage of the surrounding projects according to the construction conditions of surrounding projects, and send the rest to landfill or temporary storage yard. When backfilling is required from the completion of Project A to the later stage of the project, the transporter will also transfer the earthwork required by Project A from other projects or temporary landfill sites. This has played an important role in reducing the landfill volume of construction waste terminal. However, because transportation party itself is chasing interests in the process of construction waste disposal, so also is the important factor of construction waste control problem is one of the main performance is: the vast majority of urban construction waste transportation cost is the "front end settlement", namely the construction waste generated will use each way to transport for disposal, construction waste, and synchronization according to the capacity and settlement. Since this mode of operation fixed the total revenue of the transporter, it was inevitable that he would try to reduce the cost to increase the profit, thus leading to the phenomenon of "construction waste discarded at random nearby and leaking out".

In view in the process of transportation due to theeconomic benefits, the environment for the construction waste pollution problem occurred frequently, to alleviate the phenomenon, and the actual situation can be accurate records, and shall put the specific indicators such as litter lose balance, attribute changes, transportation vehicle control indexes into the evaluation system of the life cycle.

\subsection{Evaluation of construction waste disposal end}

Construction waste recycling is the best way to achieve green site waste disposal. The main difficulties in recycling construction waste are material pollution, economic benefits and disposal methods. According to the investigation from different demonstration cities, the disposal methods of construction waste in China are mainly classified disposal :(1) waste soil disposal in projects; (2) mud disposal in projects; (3) waste metal disposal in projects; (4) inorganic nonmetal disposal in projects; (5) concrete disposal; (6) waste bricks disposal;

(7) waste mortar disposal, etc. This method is mostly designed to promote resource recovery. However, there is still a gap in the evaluation of the disposal methods of toxic and harmful construction waste. The disposal methods of toxic and harmful construction waste are generally landfill and incineration. The vast majority of disposal sites choose incineration as the main means of solution. The method uses high temperature to decompose and remove toxic substances, and the high heat generated by the combustion process can also be used to generate electricity, but the overall cost is high. As for landfill, its low cost will cause secondary pollution to the environment and occupy land resources. Today, however, disposal landfills are equipped with impervious layers to prevent leachate from entering the environment. However, foreign research found that regardless of the nature of the impermeable layer, leachate will break through from the impermeable layer sooner or later, contaminating groundwater and critical soil.

Paying attention to the leaching characteristics of toxic substances from construction waste has become an important index for the full life cycle assessment of construction waste. Investigation includes not only toxic 
substances leaching law of vertical and horizontal, more should be to focus on its borders on soil water leaching behavior, due to the influence of factors such as surface tension, toxic substances in the junction of sports is different from pure medium, this to slow construction waste environmental impact, promote restoration of the soil and water conservation behavior is of great significance, the present evaluation is not to be classified as assessment.

\subsection{Evaluation of construction waste recycling products}

The field of renewable products has been developing slowly over the past few decades, with most renewable resources ending up in landfills. With the introduction of waste recycling, green construction and other concepts, the development of recycled products gradually put on the agenda. At present, the attention of the government of China on recycled products is focus on construction waste in terms of recycled fine aggregate, recycled coarse aggregate and recycled concrete, but there is a shortage of relevant standards on the technology, quality and comprehensive properties (physical and chemical properties) of recycled products.

Applicable tracking of recycled products is the fundamental guarantee of their existence. Only when the recycled materials prove to be useful and usable can they be accepted by the market. Applicable facts of recycled products, such as service life, application breadth and variation frequency, these attributes control the root of recycled products and should be included in the evaluation system. Through the evaluation system to further standardize the properties of recycled products, enhance the application value of recycled products, and develop related technologies.

In the demonstration cities involved in this paper, through the optimization and upgrading of the recycled products, the mature products include square bricks, permeable bricks, roadbed, aggregate, etc., to realize the deep recycling of construction waste. The recycling rate of this city has reached $95 \%$, which is a typical example of green city construction and implementation of green construction. However, after in-depth investigation, it was found that there were still loopholes in the feedback and evaluations of recycled products, and follow-up evaluations were not implemented. Therefore, in general, in the stage of regenerated products, the evaluation system still has a large shortcoming.

\section{Development potential of full life cycle evaluation of construction waste}

In order to change the current situation of construction waste disposal and fundamentally improve the technical value of construction waste full life cycle evaluation, the potential value of cycle evaluation in different stages is explored through the analysis of the whole process of construction waste, so as to improve the full life cycle evaluation system.

\subsection{Development direction of construction waste generation source evaluation}

Looking back at the past construction cases, the whole construction is often a mess, soil pollution, extreme waste of resources, building information chaos, has brought a great burden on the environment and economic costs. The traditional method of collecting construction waste information is relatively complicated, and its process is shown in Figure 2.

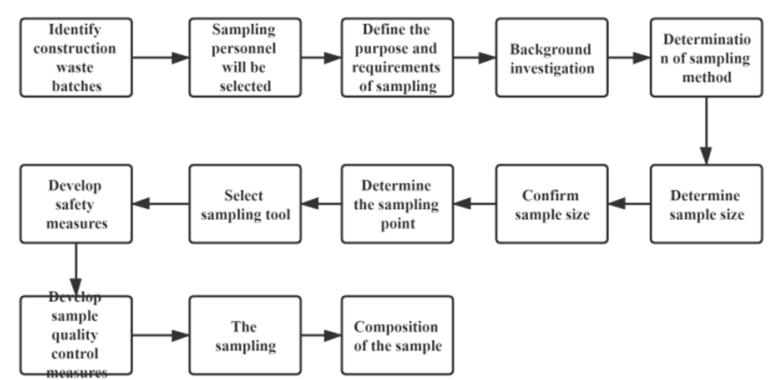

Fig2. The traditional method of collecting construction waste process

With the advent of the information age, BIM technology and green construction have injected new vitality into the whole life cycle evaluation of construction waste. BIM technology can perfectly integrate the overall information of construction projects ${ }^{[13]}$, and the establishment of relevant information model and the integration of the concept of "green construction", can deeply dig the precise point of full life cycle evaluation, to help achieve refined management.

The advantages of BIM technology are in the planning and initial stages of buildings. The technology can be used to demonstrate the design scheme in the planning stage with the full life cycle evaluation, including scheme design, cost analysis and sustainability evaluation ${ }^{[9]}$, comprehensive utilization of the site, etc., which implements the green construction with environmental protection and resource conservation as the core. Meanwhile, it is also the concrete embodiment of the theme of "sustainable development" in the project construction. Wang Ning et al. studied the technical system combining BIM and GIS, explored the precise control of construction waste, and established a real-time monitoring and intelligent control information platform for construction waste. This technology broadens the field of construction waste supervision, and combines life cycle evaluation with information technology to improve the socialized and standardized level of comprehensive utilization of construction waste, and also provides effective support for the government's monitoring and management.

With the gradual popularization of BIM and the improvement of application maturity, the application of BIM technology in building renovation projects will gradually increase, and the breadth, depth and accuracy of information provided by BIM technology will gradually increase, which will further promote the application of BIM in building renovation projects LCA. It can be predicted that there will be more and more researches on the application of BIM in building renovation LCA in the 
future, and the collaborative interaction between BIM and LCA tools will be better and better ${ }^{[10]}$.

To sum up, the visualization and simulation function of BIM shows the characteristics of green construction and green building, so that BIM can be widely used in the practice of building projects, which will also make outstanding contributions to the construction of ecological civilization in China.

\subsection{Evaluation potential of construction waste transportation}

In order to realize accurate management and accurate information evaluation of the transported wastes in the process of construction waste transportation, a series of safeguard measures, such as increasing the number of monitoring probes of transport vehicles, should be established to ensure real-time monitoring of garbage and reduce pollution to the road environment.

At present, to improve the information evaluation in the process of construction waste, the following aspects can be used to strengthen the cleaning and transportation of construction waste:

\subsubsection{Unified construction garbage collection and transportation charge system}

Unified transportation cost of construction garbage is an important link to improve the construction garbage full life cycle evaluation system and realize construction garbage collection and transportation at the same time.

\subsubsection{Strictly manage the cleaning and transportation process}

On the one hand, use the special sealing performance of the vehicle is very good, in order to avoid leakage, dust and other problems. In addition, the establishment of receipt system is a key factor to ensure the fixed-point transportation of transport vehicles, and is also an important reference information for periodic evaluation. In addition, transportation routes should be strictly inspected, such as setting UP GPS and Beidou terminals, and adding remote sensing equipment, etc., so as to realtime monitor and control the behavior of candid and disorderly shooting, so as to achieve accurate control.

Dynamic control of temporary storage points:

In order to realize the construction waste transportation can be fixed, requires the dynamic control for temporary storage of construction waste, more convenient to followup the vehicles for garbage pickup precision, is beneficial to jointly supervise each department, using information technology means to improve the evaluation system is to break the information barriers between departments, the greatest degree of fine evaluation details.

\subsection{Development direction of construction waste disposal evaluation}

The disposal site is the area where construction waste frequently pollutes the environment, so it is necessary to accurately evaluate and control the disposal site such as landfill.

\subsubsection{Explore scientific disposal techniques}

Based on the status quo of comprehensive classification of construction waste, different evaluation systems are established for different types of waste. Starting from the whole life cycle, we will study through technological reform and management policy, focusing on reducing quantitative information and supplementing classified information. Under the premise of normal guidance, actively promote the nearby reuse of construction waste, which not only effectively promotes the resource recovery of construction waste disposal, but also further improves the evaluation system. For example, the separation and disposal of waste plastics are shown in the table1 below.

Table 1-1 Recycling products and uses of waste plastics

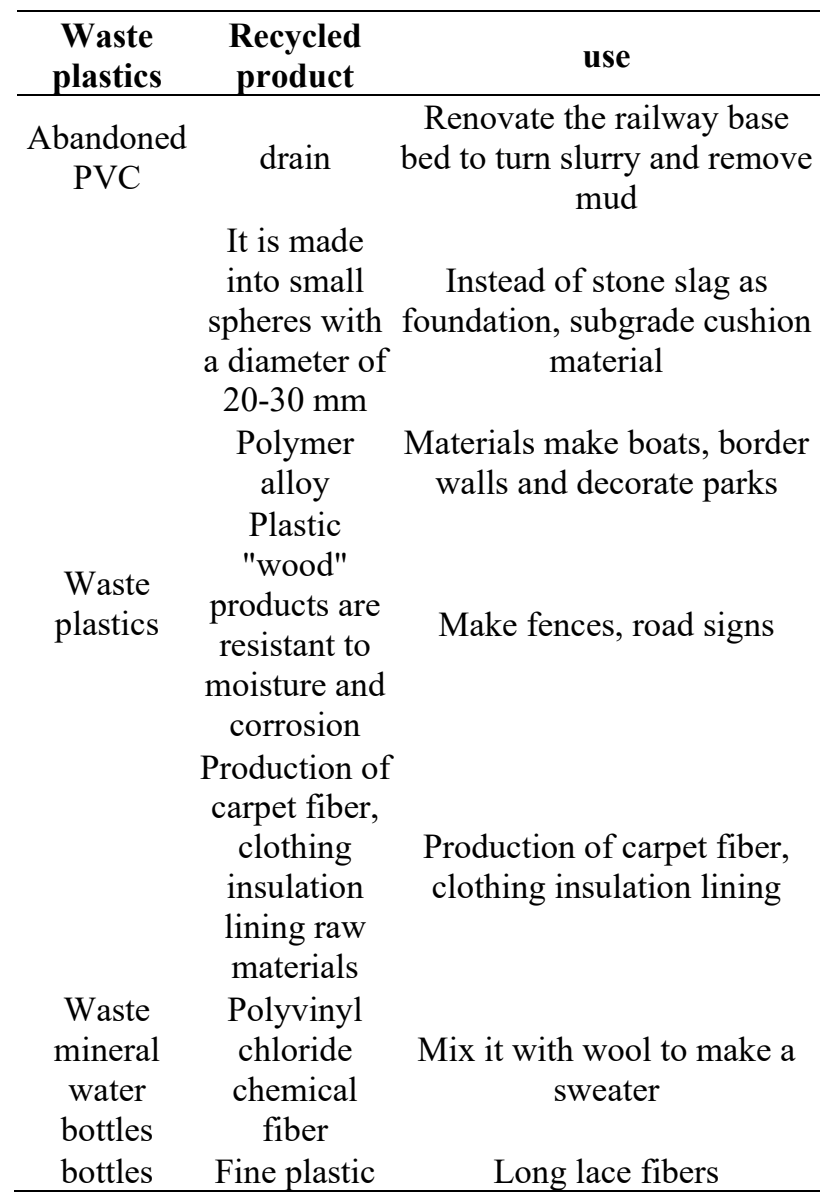

\subsubsection{Planning a reasonable disposal site}

Construction waste disposal site is not only an important urban infrastructure, but also an important source of basic data for the whole life cycle evaluation system. In the initial stage of building formation, the total amount of possible production should be predicted and strictly evaluated according to the amount of resource recovery and disposal that should be undertaken and the land scale, access system and enterprise qualification involved in the corresponding technological process ${ }^{[11]}$. 


\subsubsection{Promote the recycling of construction waste}

The biggest characteristic of construction waste is its high added value, and the best way to dispose of it is to make use of resources. Therefore, all localities and departments should actively explore ways to recycle construction waste $^{[11]}$, continuously improve the full life cycle evaluation of different approaches, increase the proportion of its resource utilization, and actively explore new technologies, new models and new evaluation system for construction waste recycling.

\subsubsection{Strengthen the evaluation system of the whole life cycle}

Accurate control of construction waste is one of the important means to improve the evaluation system, and the "Intelligent Supervision System of Construction Waste in Shenzhen" set up in Shenzhen is a typical case of accurate control and mature full life cycle evaluation system. This sharing of data breaks down existing barriers across functions ${ }^{[11]}$, making the law enforcement process no longer exist blind areas, the evaluation system no longer exist lack of loopholes, so that the overall difficulty of supervision is reduced. Many cities should learn from its advanced experience.

\subsection{Tracking and evaluation direction of construction waste recycling products}

The development of recycled products is an important channel for the recycling of construction waste, and the tracking of recycled products is the survey feedback after its practical application. The evaluation of the feedback results is conducive to expanding the development direction of the recycled products and opening up new ideas for the reclamation of construction waste. Moreover, the problems arising from the feedback results also provide opportunities for the development of the recycling technology. Therefore, the evaluation of recycled products is an important link in the whole life cycle evaluation. The current practical evaluation direction can be divided into the following parts:

\subsubsection{Evaluation of material utilization of recycled products}

Limited by the regenerative technology, the amount of recycled materials added in most of the regenerative products is inversely proportional to the performance of the final product. So how to allocate the proportion of recycled materials in recycled products has become a hot topic at present. This ratio not only affects the properties of finished products, but also relates to whether the recycling technology has been used. It is an important evaluation index to evaluate whether a resource chemical plant carries out the recycling technology. Therefore, in the future, it should be an important link to evaluate the utilization rate of renewable resources of different renewable products on the premise of not affecting their normal service life and use properties.

\subsubsection{Deformation evaluation of recycled products}

In the practical application process, the physical and chemical properties of the regenerated products will be denaturated to a certain extent with the different application scenarios. At present, there are kinds of research in this field, such as compressive strength and tensile strength indexes of recycled concrete, water absorption rate and water permeability indexes of recycled aggregate, etc. However, a large number of studies have only focused on the degeneration of recycled products in different cases. However, the denaturation evaluation of commonly used recycled products in a certain field is still in the blank stage, and most of the performance evaluation is still in the fragmentation stage. In the future, the performance evaluation of recycled products can focus on the commonly used recycled products in an industry, so as to form a relatively complete performance evaluation system of recycled products.

\subsubsection{Market evaluation of recycled products}

The market evaluation is mainly divided into the application scope evaluation and the application depth evaluation of the recycled products. As for the application scope of the recycled product, it shows the market potential of the recycled product and whether it has the future development space. The evaluation result directly affects the corresponding production technology and the recycling rate of some waste. In addition, the in-depth evaluation of application lies in whether the regenerated product can be used in high-end industries to meet the needs of some large markets, which is conducive to the expansion of the application of the regenerated product.

\section{Summary}

The whole life cycle evaluation of construction waste not only aims at improving the whole construction waste industry chain, but also is an important measure to promote the development of green construction and green construction in China. Through the in-depth analysis of the four links of source, transportation, terminal and product, new requirements and ideas are proposed for the whole cycle evaluation, and the shortage and development direction of construction waste recycling are further summarized to constantly improve its recyclable products. The evaluation of life cycle implements the development strategy of sustainable development, conforms to the new development concept of "clear water and green mountains are gold and silver mountains" proposed by President Xi jinping, and provides a technical guarantee for the sustainable and healthy development of national economy, as well as a new evaluation system for the construction of national ecological civilization.

\section{Acknowledgement}

This work was financially supported by the National Key Research and Development Project (2018YFC0706000) and the Fundamental Research Funds of Beijing Jiaotong 
University (2020JBZ112).

\section{References}

1. Huang Zhong. Game Analysis and Development Strategy Research on sales link of construction waste Recycling Products [D].Shaanxi: Xi 'an University of Architecture and Technology, (2018).

2. Liu Xia, HU Xi. Research on the Quantitative Method of construction waste based on the whole life cycle [J]. Science and Technology Innovation,(2020),(2):175176.

3. Liu Hua. Theory and Method of green Product evaluation and its application in powder metallurgy Guangdong: South China University of Technology,2005.

4. Tang L L. Life Cycle environmental Impact Assessment of construction waste Treatment [J]. Renewable Resources and Circular Economy, 209 (6):29-31.

5. Wang Ning, Lou Dai, Chen Daqing, et al.Preliminary Study on the Construction waste Accurate control Information Management Platform based on "BIM+GIS" technology [J].Environmental engineering, 2020, 20 (3) : 46-50.

6. Bai Lu, SUN Qihong, Qiao Qi.Review on the progress of life cycle evaluation in China $[\mathrm{J}]$. Anhui agricultural science,(2010),38(5):2553-2555.

7. Chen Yamin. Preliminary study on land use Ecological Impact Assessment method in LCA [D]. Shanghai: Fudan University,(2012).
8. Wang Bo. Study on the treatment Model of construction waste in Shenzhen Based on life cycle Evaluation [D]. Hubei: Huazhong University of Science and Technology, 2012. DOI:10.7666/d.D230636.

9. Yang Keren. Application Research of Architectural Design Quality Evaluation based on BIM Technology [D]. Shaanxi: Xi 'an University of Architecture and Technology,2018.

10. Yang Xining. Study on environmental Impact Assessment of the Life cycle of Building Renovation Project based on BIM [D].Chongqing: Chongqing University,(2018).

11. Xie Zhifeng, ZHAO Jinzhu.Treatment, Disposal, utilization and Countermeasures of Construction waste in China $[\mathrm{J}]$. Urban Construction Theory Research (Electronic Version),(2011),(27).

12. $\mathrm{Hu}$ Chunwei. Application of BIM Technology in Construction Engineering Management $[\mathrm{J}]$.

Construction Engineering Technology and Design,2018,(11):3301.

13. Hua Wei. Study on construction waste Management in Henan Province [D]. Henan: Zhengzhou University,(2017). 